\title{
ENHANCING MECHANICAL AND SURFACE PROPERTIES OF Eucalyptus WOOD
}

\author{
Anderson Pertuzzatti ${ }^{1}$, Gianluca Tondi ${ }^{2,3}$, Rodrigo Coldebella ${ }^{1}$, Henrique W. Dalla Costa ${ }^{1}$, Ronan Corrêa ${ }^{1}$, \\ Darci A. Gatto ${ }^{1,4}$, André L. Missio ${ }^{1,5, \mathrm{~s}}$
}

\begin{abstract}
Eucalyptus is one of the most fast-growing trees. Therefore, in the last decades it has been extensively planted and harvested so that nowadays Eucalyptus is one of the most popular trees of the planet. There are many genres of this plant and they are often treated as a large bunch of the same timber characterized by moderate mechanical and surface properties which hinder their usage for any sight application (e.g. flooring, cladding, ceiling). In this study four species of Eucalyptus: E. grandis, E. dunnii, E. cloeziana and E. tereticornis were undergone to densification through hydro-thermo-mechanical treatment (HTM) first and then to oil heat-treatment (OHT) in order to improve their mechanical properties and hydrophobicity. It was observed that low density species (E. grandis) reaches higher compression degrees while heavier species (E. tereticornis) reach densities over $800 \mathrm{~kg} / \mathrm{m}^{3}$; however, HTM decrease the variability of the properties. Treatments at higher temperature $\left(160{ }^{\circ} \mathrm{C}\right)$ involves higher compression degree, lower set-recovery and higher surface hydrophobization, but also weaker mechanical properties. The hot oil post- treatment helps to contain the springback effect and to reduce the wettability of each specimen. Densified samples present similar surface hardness. The tailored application of the two treatments improves the properties of every Eucalyptus which can gain market also for nobler end-usages.
\end{abstract}

Keywords: Density enhancement, mechanical resistance, post-treatment, springback effect, surface properties, synergic treatment, wettability.

\section{INTRODUCTION}

Until the middle of the last century there was a wide variety of forest species available in Brazil. But the massive harvesting of tropical lumbers has dramatically reduced the stock available and wood with excellent mechanical and durability properties became scarce and expensive. The increasing need for wood has favoured the plantation of fast-growing trees and since then the Eucalyptus species are the most abundant in Brazil. Several Eucalyptus species were introduced, but due to the limited experience with this specie, they were often harvested jointly and underwent the same processing line, even though their properties are sensibly different.

Due to its features, Eucalyptus is particularly interesting for pulping purposes, but it cannot be used for flooring, cladding, ceiling or any other application were mechanical and durability resistance are required.

In this context, a wood modification process that enhances mechanical and surface properties and also

${ }^{1}$ Forestry Engineering (PPGEF), Forest Products Laboratory, Centre for Rural Sciences, Federal University of Santa Maria, Santa Maria, Brazil.

${ }^{2}$ Forest Products Technology \& Timber Construction Department, Salzburg University of Applied Sciences, Kuch, Austria.

${ }^{3}$ University of Padua, Department of Land, Environment, Agriculture and Forestry, Padua, Italy.

${ }^{4}$ Faculty of Materials Engineering (PPGCEM), Federal University of Pelotas, Pelotas, Brazil.

${ }^{5}$ Materials Engineering Course, Technological Development Center (CDTec), Federal University of Pelotas, Pelotas, Brazil.

•Corresponding author: andreluizmissio@gmail.com

Received: 08.08.2019 Accepted: 26.05.2020 
homogenises the different species is necessary. These modification methods, whether of thermal treatments or also using densification, are currently used by researchers in different species, such as Pinus caribaea and Eucalyptus saligna (Brito et al. 2019), Eucalyptus nitens (Wentzel et al. 2019), Eucalyptus grandis and Eucalyptus cloeziana (Dalla Costa et al. 2020), Fagus sylvatica and Quercus robur (Laskowska 2020), Populus usbekistanica (Sözbir et al. 2019), aiming at increases in the technological properties of wood. The densification process suites well to this purpose because it is proven to significantly increase the mechanical and surface properties of wood (Welzbacher et al. 2008, Pertuzzatti et al. 2018).

The technique of timber densification was already presented more than a century ago and in the last decades it is evolved to hydro-thermo-mechanical treatment (HTM) consisting of multi-stage process of wet/ moist cycles at various temperatures and pressure (Sears 1900, Welzbacher et al. 2008, Navi and Pizzi 2015).

The major drawback of the resulting compressed wood is the springback effect which occurs when the material is exposed to high moisture environment or in direct contact with water. Several studies involving resin impregnation, thermal and oil based post-treatment were already studied to minimize this effect (Gabrielli and Kamke 2010, Gong et al. 2010, Fang et al. 2012) and the oil heat-treatment (OHT) have the additional advantage of increasing the biological resistance of the treated samples (Dubey et al. 2012, Pelit et al. 2015).

Other studies have shown that the densification at $>180{ }^{\circ} \mathrm{C}$ carries to a significant reduction of the mechanical properties (Navi and Pizzi 2015, Pelit et al. 2015, Pertuzzatti et al. 2018), whereas when too low temperature are applied, the springback effect is remarkable and a stabilizing post-treatment is required (Dubey et al. 2012). For this reason, in this study, we investigate the technological properties of the wood treated at $140{ }^{\circ} \mathrm{C}$ and $160{ }^{\circ} \mathrm{C}$ and applying the OHT to find the most suitable treatment for enhancing the properties of the four Eucalyptus species considered (E. grandis, E. dunnii, E. cloeziana and E. tereticornis).

\section{MATERIAL AND METHODS}

\section{Materials}

Eucalyptus grandis, Eucalyptus dunnii, Eucalyptus cloeziana and Eucalyptus tereticornis trees of 21, 18, 20 and 22 years respectively were abated in the region of Santa Maria - RS, Brasil (29 $43^{\circ} 1,95^{\prime \prime}$ S, 53 $43^{\circ}$ $\left.33,7^{\prime \prime} \mathrm{W}\right) .5$ trees for each species were selected according to the ASTM D5536-94 (2004). Each sample was extracted from the region at around $3 \mathrm{~m}$ from the tree base, by selecting knots-free heartwood (Missio et al. 2016).

60 samples of $40 \mathrm{~cm} \times 15 \mathrm{~cm}$ and different thickness according to density, were prepared and stabilized until equilibrium moisture content ( 30 days under conditions $-20{ }^{\circ} \mathrm{C}$ and $65 \%$ of relative humidity) in order to obtain samples having thickness of $2 \mathrm{~cm}$ after densification.

\section{Sample preparation}

\section{Hydro-thermo-mechanical treatment (HTM) - densification}

Eucalyptus samples were initially pre-heated by dipping in $100{ }^{\circ} \mathrm{C}$ water for $20 \mathrm{~min}$. After short blotting, the samples were compressed in radial direction with $6 \mathrm{MPa}$ pressure at $140{ }^{\circ} \mathrm{C}$ or $160{ }^{\circ} \mathrm{C}$ for 40 min (Arruda and Del Menezzi 2016). The samples were measured and stabilized in a climatic chamber $\left(20{ }^{\circ} \mathrm{C}\right.$ and $65 \%$ RH) until equilibrium was reached.

\section{Oil heat treatment (OHT)}

The stabilized samples were dipped into an oil bath, filled with refined soybean oil (Type 1, density $\sim 922$ $\mathrm{kg} / \mathrm{m}^{3}$ at $20^{\circ} \mathrm{C}$ ), at $180^{\circ} \mathrm{C}$ for $60 \mathrm{~min}$ and then dried in a ventilated oven at $103{ }^{\circ} \mathrm{C}$ for a standard time of one hour. Finally, the samples were stabilized again $\left(20^{\circ} \mathrm{C}\right.$ and $\left.65 \% \mathrm{RH}\right)$. The treatments applied are summarized in Table 1. 
Table 1: Hydro-thermo-mechanical (HTM) treatments on Eucalyptus grandis, Eucalyptus dunnii, Eucalyptus cloeziana and Eucalyptus tereticornis.

\begin{tabular}{|l|c|c|c|}
\hline Wood species & Treatment & HTM, Temperature $\left({ }^{\circ} \mathbf{C}\right)$ & OHT at $\mathbf{1 8 0}{ }^{\circ} \mathbf{C}$ \\
\hline \multirow{3}{*}{$\begin{array}{l}\text { E. grandis } \\
\text { E. dumnii }\end{array}$} & EC & No treatment & No \\
\cline { 2 - 4 } E. cloeziana & EC-T & No treatment & Yes \\
\cline { 2 - 4 } E. tereticornis & E140 & 140 & No \\
\cline { 2 - 4 } & E140-T & 140 & Yes \\
\cline { 2 - 4 } & E160 & 160 & No \\
\cline { 2 - 4 } & E160-T & 160 & Yes \\
\hline
\end{tabular}

\section{Sample characterization}

\section{Physical analysis}

The Compression degree $(\mathrm{Cd})$ was calculated from the relationship between final and initial thickness of the wooden pieces (Equation 1), measured with a digital caliper $(0,01 \mathrm{~mm})$ immediately after the hydro-thermo-mechanical treatment.

$$
\mathrm{C}_{\mathrm{d}}=\left(\mathrm{T}_{\mathrm{i}}-\mathrm{T}_{\mathrm{f}} / \mathrm{T}_{\mathrm{f}}\right) \times 100(\%)
$$

Where $T_{i}$ is the initial thickness (mm), $T_{f}$ is the final thickness (mm), $T_{a}$ is the thickness of the dry sample after $24 \mathrm{~h}$ water immersion $(\mathrm{mm})$.

The mass variation (MV) was performed using the relation between the mass of the samples before and after densification (Equation 2). This step was important to determine the influence on the mass of the samples after each step of modification treatments.

$$
M V=\left(\frac{M_{A d}-M_{B d}}{M_{B d}}\right) \times 100(\%)
$$
$(\mathrm{kg})$.

where $M_{B d}$ is the sample dry mass before densification $(\mathrm{kg}), M_{A d}$ is the sample dry mass after densification

The density of the samples $\left(\rho_{b}\right)$ was performed under the condition of $12 \%$ relative humidity $\left(20^{\circ} \mathrm{C}\right.$ and $65 \% \mathrm{RH})$ using Equation 3.

$$
\rho_{b}=M / V
$$

Where $M(\mathrm{~kg})$ is the mass of the samples in the condition of $12 \%$ relative humidity $\left(20{ }^{\circ} \mathrm{C}\right.$ and $\left.65 \% \mathrm{RH}\right)$, and $V\left(\mathrm{~m}^{3}\right)$.is the sample volume in the condition of $12 \%$ relative humidity $\left(20{ }^{\circ} \mathrm{C}\right.$ and $\left.65 \% \mathrm{RH}\right)$

Set recovery (SR) was measured by dipping the samples in a $20{ }^{\circ} \mathrm{C}$ water bath for 24 hours and successively drying them at $103{ }^{\circ} \mathrm{C}$ until constant mass. The final thickness $\mathrm{Ta}$ was registered and SR was calculated according to Equation 4. This calculation is essential for calculating the springback effect.

$$
S R=\left(\left(\frac{T_{a}-T_{f}}{T_{i}-T_{f}}\right) \times 100_{f}\right) \times 100(\%)
$$

where $T_{i}$ is the initial thickness (mm), $T_{f}$ is the final thickness (mm), $T_{a}$ is the thickness of the dry sample after $24 \mathrm{~h}$ water immersion ( $\mathrm{mm})$. 


\section{Mechanical analysis}

Bending, compression and Janka hardness were performed on 12 samples per treatment with a universal testing machine EMIC® DL2000/1000. The bending tests were performed according to the ASTM D143-94 (2000) with a rate of $1,04 \mathrm{~mm} / \mathrm{min}$ on samples of $32 \mathrm{~cm} \times 2 \mathrm{~cm} \times 2 \mathrm{~cm}$ and elastic modulus (MOE) and rupture modulus (MOR) were registered. The compression tests were done following ASTM D143-94 (2000) on samples of $10 \mathrm{~cm} \times 2 \mathrm{~cm} \times 2 \mathrm{~cm}$. The Janka tests were run on the compressed face by using a spherical spot with $1 \mathrm{~cm}^{2}$ of surface with a penetration rate of $6 \mathrm{~mm} / \mathrm{min}$.

Impact resistance was measured according to ABNT NBR 7190 (1997), with a Charpy pendulum (PW

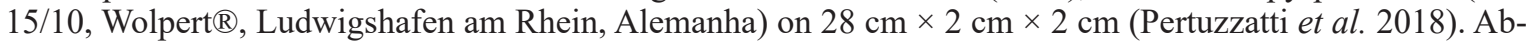
sorbed work $(\mathrm{W})$ and maximal resistance $\left(\mathrm{F}_{\max }\right)$ were calculated Equation 5.

$$
F_{\max }=100 \times \frac{W}{b} \times h
$$

where $F_{\max }$ is the maximum resistance to impact $\left(\mathrm{kJ} / \mathrm{m}^{2}\right), W$ is the absorbed work $(\mathrm{J})$, and $b$ and $h$ are the transverse sample dimensions $(\mathrm{mm})$.

\section{Wettability}

Contact angle (CA) measurements were done with a DataPhysics OCA (DSA 25, Krüss, Hamburg, Germany) instrument at $20{ }^{\circ} \mathrm{C} \pm 1{ }^{\circ} \mathrm{C}$ laying $5 \mu \mathrm{L}$ drop of deionized water on the compressed face of the stabilized specimens. The contact angle was registered after $10 \mathrm{~s}, 30 \mathrm{~s}, 50 \mathrm{~s}, 70 \mathrm{~s}$ and $90 \mathrm{~s}$.

\section{Data analysis}

Normality and homogeneity tests of variance were verified with White and Shapiro-Wilk algorithm, respectively. Variance analysis (ANOVA) was performed and the comparison between averages was done with the Tukey test $(<5 \%)$ with the SISVAR program (Ferreira 2011).

\section{RESULTS AND DISCUSSION}

\section{Intrinsic properties}

During the HTM densification process, volume, mass and hence density of the treated samples modified. In Figure 1 compression degree (a), mass variation (b), density (c) and set-recovery after water cycle (d) are presented.

Applying the same pressure to different Eucalyptus species carries to different thicknesses and the compression degree is summarized in Figure 1a. It can be noticed that the original density as a major impact on the compression degree: the lower was the original density, the higher was the compression degree. This phenomenon is well-known in the literature and it is due to the fact that a lighter timber, has also more voids (Unsal et al. 2011). It is interesting to observe that the use of higher temperature involved higher compression degrees for every species. This was also a logical consequence because the thermoplastic lignin become softer at higher temperature and hence the specimens result more compressed (Bekhta et al. 2012, Wolcott et al. 1990, Welzbacher et al. 2008).

Mass loss (Figure 1b) also occurred when wood was subjected to HTM densification processes. On the one hand the volatile substances (e.g. VOC, water) and the small moieties obtained by thermal degradation of hemicelluloses evaporated during the process and on the other hand the equilibrium moisture content after treatment was lower because of the less hydrophilic surface which equilibrated with less water (Alén et al. 2002, Pertuzzatti et al. 2018). Consistently, higher mass losses were observed when higher densification temperature were applied. 

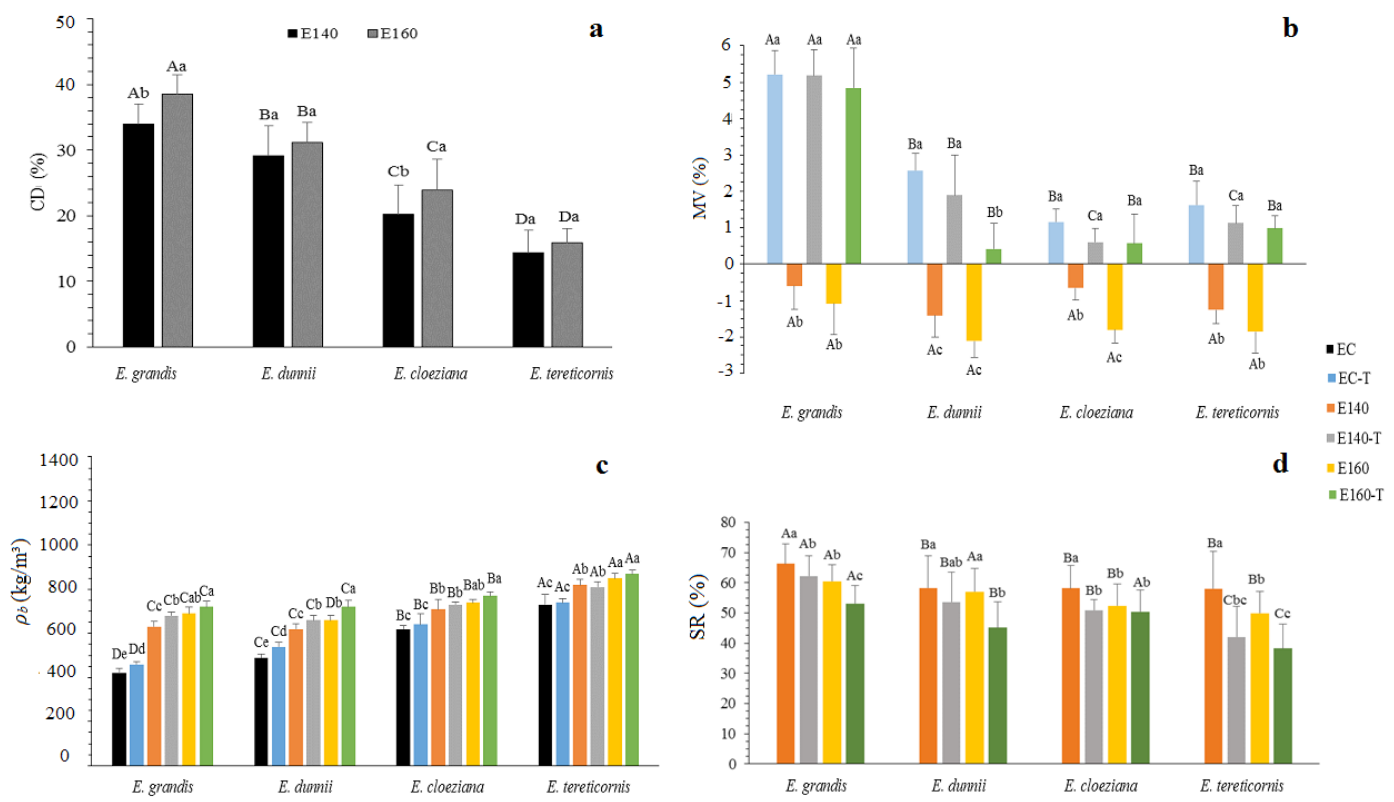

Figure 1: Intrinsic properties of densified and oil post-treated Eucalyptus. (a) Compression degree; (b) Mass variation; (c) Density and (d) Set recovery (\%).

The standard deviation is reported on top of each bar. The capital letters describe the comparison between species while the lowercase compare between treatments according to Tukey test $5 \%$ significance.

When the samples underwent post-treatment with oil bath OHT, the mass variation was positive because of the penetrated oil, but also in these cases lower absorptions and higher chemical degradations were observed for the more compressed samples.

As a consequence of the previous two greatness, density increases were registered for every densification and oil treatment (Figure 3c) meaning that the mass loss is less important than the volume decrease. Volume reductions from $13,3 \%$ to $38,5 \%$ and the weight reduction of $0,6 \%$ to $2,2 \%$ resulting in a density increase of $10,9 \%$ to $61,9 \%$ were observed.

The density increase registered during densification was more important for the species with originally lower density $\left(420 \mathrm{~kg} / \mathrm{m}^{3}\right)$ which achieved $\min .630 \mathrm{~kg} / \mathrm{m}^{3}$ while the heavier species $\left(730 \mathrm{~kg} / \mathrm{m}^{3}\right)$ reached max. density of $870 \mathrm{~kg} / \mathrm{m}^{3}$. The effect of the oil post-treatment showed density gain of around $30 \mathrm{~kg} / \mathrm{m}^{3}$, but also in this case the lighter wood E. grandis and E. dunnii absorbed more oil (approximately $45 \mathrm{~kg} / \mathrm{m}^{3}$ ) while the heavier E. cloeziana and E. tereticornis adsorbed less (approximately $15 \mathrm{~kg} / \mathrm{m}^{3}$ ). Overall the density between the different Eucalyptus homogenized, but still significant differences were observed: The natural densities of E. grandis $\left(420 \mathrm{~kg} / \mathrm{m}^{3}\right)$ and E. tereticornis $\left(730 \mathrm{~kg} / \mathrm{m}^{3}\right)$ was very different $\left(\Delta=310 \mathrm{~kg} / \mathrm{m}^{3}\right)$ while the samples compressed at $180^{\circ} \mathrm{C}$ had density of $720 \mathrm{~kg} / \mathrm{m}^{3}$ and $870 \mathrm{~kg} / \mathrm{m}^{3}$ respectively $\left(\Delta=150 \mathrm{~kg} / \mathrm{m}^{3}\right)$.

The set-recovery highlighted that significant springback effect occurred for every treatment. The densification temperature had a lower impact in reducing the set recovery compared to the oil post-treatment, while the original wood density had also a considerable importance, since the E. tereticornis presented significantly lower set-recoveries (down to $35 \%$ ).

According to Navi and Pizzi 2015, there are two mechanisms acting on set-recovery. After densification, the wood is cooled below the glass transition temperature of lignin, that is, from rubbery to the glassy state. In this way, cellulose will be confined in this rigid matrix. During drying, the formation of hydrogen bonds between the cell wall polymers also contributes to the fixation of the deformed state. However, if the wood comes into contact with water or variations in relative humidity, the hydrogen bonds disrupt, and lignin may become rubbery again. On the one hand, the hydrolysis of hemicelluloses during densification plays an active 
role in the dissipation of the tensions stored. During the hemicelluloses hydrolysis, more porous surfaces are formed which allow to dissipate the deformation energy. These changes in hemicelluloses result in decreases in mechanical properties (similar to thermal treatments), which would make the wood modification method unfeasible. Thus, there must be a balance between depolymerization of hemicelluloses, changes from $\mathrm{Tg}$ of lignin and densification rates, aiming at the minimum loss of mechanical resistance.

\section{Mechanical properties}

Bending, compression and the impact resistances as well as the surface hardness were measured to evaluate the effects of the treatments on the Eucalyptus species. These tests are summarized in Figure 2 and show that generally the densified wood increase all mechanical properties: up to $22 \%$ in MOE, up to $34 \%$ in MOR, up to $80 \%$ in s max, up to $218 \%$ in hardness and up to $94 \%$ in impact resistance. In particular, the wood densified at milder temperature and without post-treatment were better performing against all mechanical solicitations. This result was confirmed for all species of Eucalyptus.

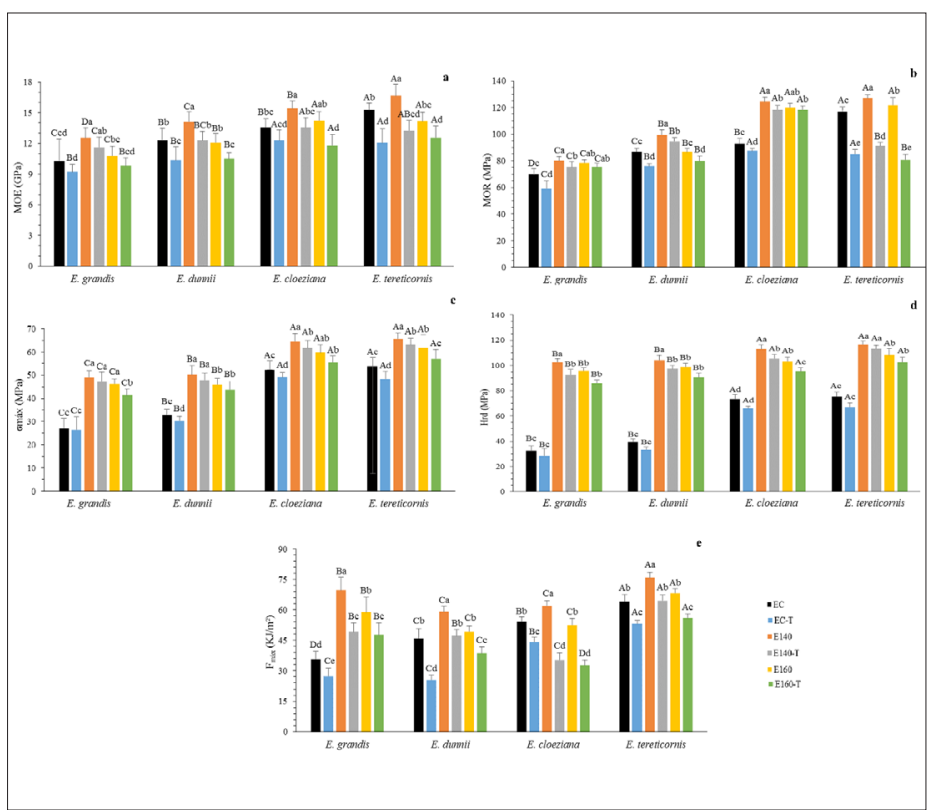

Figure 2: Mechanical properties of densified and oil- post-treated Eucalyptus. (a) Modulus of elasticity (MOE); (b) Modulus of rupture (MOR); (c) Compression resistance ( $\sigma$ máx) (d) Janka hardness (Hrd) and (e) Impact resistance $\left(\mathrm{F}_{\text {máx }}\right)$.

The standard deviation is reported on top of each bar. The capital letters describe the comparison between species while the lowercase compare between treatments according to Tukey test $5 \%$ significance.

The mechanical properties analysed worsen by applying higher temperature and/or oil treatment. These results were due to the degradation of the structure when more aggressive thermal treatment is applied. Thermal treatments caused the increase of micro-fractures, (Ulker et al. 2012, Navi and Pizzi 2015, Gašparík et al. 2016, Gaff et al. 2017, Pelit et al. 2018, Pertuzzatti et al. 2018) and the hot oil at $180^{\circ} \mathrm{C}$ further weakened the structure because the it penetrated the surface and facilitated the heat transfer with consequent increase of degradation inside of the wood structure.

The densification process significantly enhanced the surface hardness. This was due to the nature of the process which compress to a higher extent the surface layers that results denser than the inner core. The surface hardness after compression was similar for all the considered genres of Eucalyptus and therefore when hardness had a major impact (e.g. flooring purposes), the variability of Eucalyptus can be reduced with the densification process. The surface hardness had also particularly high impact in the surface wettability. 


\section{Wettability}

In Figure 3 the contact angle measurements at different time were registered for every treatment and species. The oil treated specimens showed the more hydrophobic behavior with similar contact angles (between $90^{\circ}$ and $110^{\circ}$ ) for E. grandis, E. cloeziana and E. dunnii, while the specimens of E. tereticornis showed slightly higher values (over $120^{\circ}$ for the treatment at $160^{\circ} \mathrm{C}$ ) and this was due to their higher density (Amorim et al. 2013). Specimens densified at higher temperatures, resulted more hydrophobic than the homologues treated at milder temperatures while the samples undergoing only oil treatment presented similar trend than the sample densified but not oil-treated, meaning that the two processes allow similar enhancements. The specimens treated only with oil showed steeper slopes than the HTM densified samples which suggest that the OHT modification involves prolonged hydrophobic behavior. This was possibly due to the smoother surface of the densified samples (Christiansen 1991, Pertuzzatti et al. 2016).

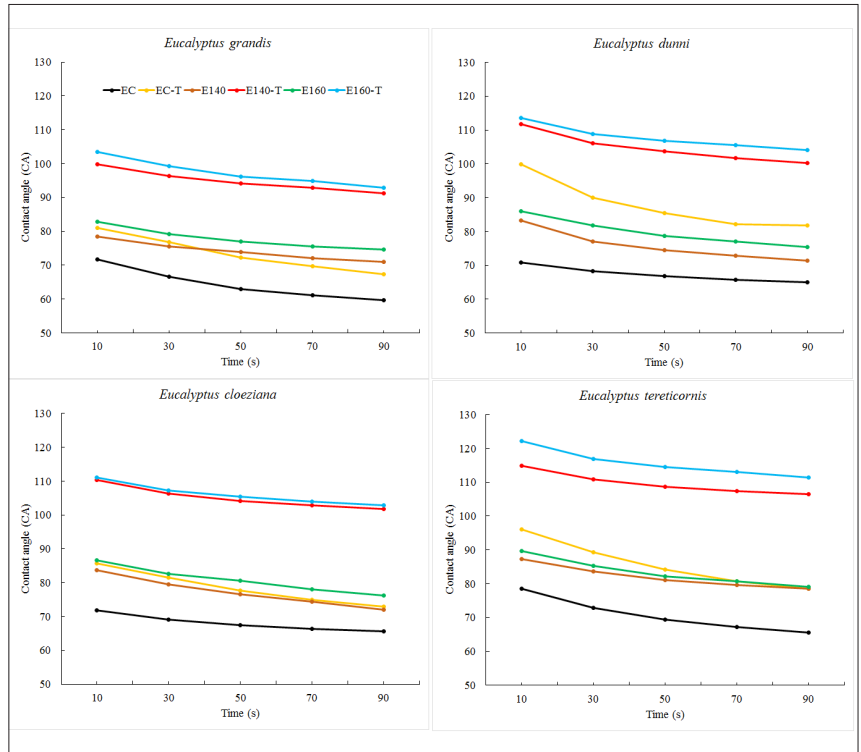

Figure 3: Contact angle trend over time for the four Eucalyptus species undergoing densification and oil post-treatment.

According to Wålinder and Gardnerb (1999), when the water drop lays with contact angle $<90^{\circ}$ a faster penetration, typical for hydrophilic surfaces, occurs. This means that without oil post-treatment the densification process alone does not guarantee to significantly modify the wettability to hydrophobic and the surface can still be easily treated with coatings and adhesives. Conversely, when the HTM densification and the OHT oil post-treatment are combined, the contact angle increases of around $50 \%$ and wood surface remains hydrophobic for longer than 90 seconds.

Considering the average price of Eucalyptus $\left(\mathrm{d}=550 \mathrm{~kg} / \mathrm{m}^{3}\right)$ of $215 \$ / \mathrm{m}^{3}$ we can estimate the cost of the densified wood after HTM treatment to around $378 \$ / \mathrm{m}^{3}\left(\mathrm{~d}=700 \mathrm{~kg} / \mathrm{m}^{3}\right)$. The OHT post-treatment can be estimated with $130 \$ / \mathrm{m}^{3}$ and therefore the cost of the HTM and OHT treated wood will be around $509 \$ / \mathrm{m}^{3}$. This price is highly competitive because with the mechanical and surface properties observed promote the densified Eucalyptus can be considered also for flooring and cladding applications for which tropical species like Mogno (Swietenia macrophylla), Ipê (Tabebuia sp.) and Cedrus (Cedrela fissilis) are used and their costs is, at present, around $790 \$ / \mathrm{m}^{3}$.

\section{CONCLUSIONS}

In the present study we have analysed intrinsic, mechanical and surface properties of four Eucalyptus species undergoing $\mathrm{HTM}$ treatment at $140{ }^{\circ} \mathrm{C}$ and $160^{\circ} \mathrm{C}$ with an OHT hot-oil post-treatment. 
It was observed that limited loss of mass and consistent loss of volume with resulting increase of density were registered for every Eucalyptus species. In particular, the ones having lower density reached higher compression degrees and the ones originally heavier reached density over $800 \mathrm{~kg} / \mathrm{m}^{3}$ after HTM process and presented reduced set-recovery after water immersion (down to $<40 \%$ ). The study of the mechanical properties highlighted that milder HTM treatment produces more performing densified wood for bending, compression, impact and mostly hardness resistance. Both, densification and oil post-treatment increased significantly the hydrophobicity of the wood surface, but only the joint application of the two treatments allowed to get surfaces with contact angle $>90^{\circ}$. The densification process enhanced the mechanical properties and homogenized the properties of the four Eucalyptus species studied, while the hot-oil post-treatment was required to obtaining a more hydrophobic surface and for containing the springback effect. The combination of the two treatments carried to an interesting, cheap biomaterial that can be suitable for indoor sight application such as flooring, cladding and ceiling.

\section{ACKNOWLEDGMENTS}

To the Coordination for the Improvement of Higher Education Personnel (CAPES Foundation), for the granting of financial support and PNPD scholarship (National Postdoctoral Program) to the author André Luiz Missio - process number: 88887.475364/2020-00.

\section{REFERENCES}

ABNT. NBR. 1997. Projeto de Estruturas de Madeira. ABNT. NBR 7190. 1997. São Paulo, SP, Brazil.

Alén, R.; Kotilainen, R.; Zaman, A. 2002. Thermochemical behavior of Norway spruce (Picea abies) at 180-225 ${ }^{\circ}$ C. Wood Sci Technol 36(2): 163-171. https://doi.org/10.1007/s00226-001-0133-1

Amorim, M.R.S.; Ribeiro, P.G.; Martins, S.A.; Menezzi, C.H.S.; Souza, M.R.D. 2013. Surface wettability and roughness of 11 Amazonian tropical hardwoods. Floram Forest Ambient 20(1): 99-109. http://dx.doi.org/10.4322/floram.2012.069

Arruda, L.M.; Del Menezzi, C.H.S. 2016. Properties of a laminated wood composite produced with thermomechanically treated veneers. Adv Mater Sci Eng 2016: 1-9. https://doi.org/10.1155/2016/8458065

ASTM. D143-94. 2000. Standards methods of testing small clear specimens of timber. West Conshohocken, PA, USA. https://doi.org/10.1520/D0143-94

ASTM. 2004. Standard practice for sampling forest trees for determination of clear wood properties. ASTM. D5536-94. 2004. West Conshohocken, PA, USA. https://doi.org/10.1520/D5536-94R04

Bekhta, P.; Niemz, P.; Sedliacik, J. 2012. Effect of pre-pressing of veneer on the glueability and properties of veneer-based products. Eur $J$ Wood Wood Prod 70(1-3): 99-106. https://doi.org/10.1007/s00107-010-0486-y

Brito, J.O.; Dias Júnior, A.F.; Lana, A.Q.; Andrade, C.R.; Bernardes, F.F. 2019. Biological resistance of heat-treated wood of Pinus caribaea and Eucalyptus saligna. Maderas-Cienc Tecnol 21(2): 223-230. http://dx.doi.org/10.4067/S0718-221X2019005000209

Christiansen, A.W. 1991. How overdrying wood reduces its bonding to phenol-formaldehyde adhesives: a critical review of the literature. Part II, Chemical reactions. Wood Fiber Sci 23(1): 69-84. https://wfs.swst.org/index.php/wfs/article/view/2105

Dalla Costa, H.W.; Coldebella, R.; Andrade, F.R.; Gentil, M.; Correa, R.; Darci A. Gatto, D.A.; Missio, A.L. 2020. Brittleness increase in Eucalyptus wood after thermal treatment. Int Wood Prod J 11(1): 38-42. https://doi.org/10.1080/20426445.2020.1719298 
Dubey, M.K.; Pang, S.; Walker, J. 2012. Changes in chemistry, color, dimensional stability and fungal resistance of Pinus radiata D. Don wood with oil heat-treatment. Holzforschung 66(1): 49-57. https://doi.org/10.1515/HF.2011.117

Fang, C.H.; Mariotti, N.; Cloutier, A.; Koubaa, A.; Blanchet, P. 2012. Densification of wood veneers by compression combined with heat and steam. Eur J Wood Wood Prod 70(1-3): 155-163. https://doi.org/10.1007/s00107-011-0524-4

Ferreira, D.F. 2011. Sisvar: a computer statistical analysis system. Cienc Agrotec 35(6): 1039-1042. https://doi.org/10.1590/S1413-70542011000600001

Gabrielli, C.; Kamke, F. 2010. Phenol-formaldehyde impregnation of densified wood for improved dimensional stability. Wood Sci Technol 44(1): 95-104. https://doi.org/10.1007/s00226-009-0253-6

Gaff, M.; Babiak, M.; Vokatý, V.; Gašparík, M.; Ruman, D. 2017. Bending characteristics of hardwood lamellae in the elastic region. Compos Part B-Eng 116(1): 61-75. https://doi.org/10.1016/j.compositesb.2016.12.058

Gašparík, M.; Gaff, M.; Šafaříková, L.; Vallejo, C.R.; Svoboda, T. 2016. Impact Bending Strength and Brinell Hardness of Densified Hardwoods. BioResources 11(4): 8638-8652. https://ojs.cnr.ncsu.edu/index.php/ BioRes/article/view/BioRes_11_4_8638_Gasparik_Impact_Bending_Strength_Brinell_Hardness

Gong, M.; Lamason, C.; Li, L. 2010. Interactive effect of surface densification and postheat-treatment on aspen wood. Journal of Materials Processing Technology 2010(2): 293-296. https://doi.org/10.1016/j.jmatprotec.2009.09.013

Laskowska, A. 2020. The influence of ultraviolet radiation on the colour of thermo-mechanically modified beech and oak wood. Maderas-Cienc Tecnol 22(1): 55-68. http://dx.doi.org/10.4067/S0718-221X2020005000106

Missio, A.L.; Cademartori, P.H.G.; Mattos, B.D.; Santini, E.J.; Haselein, C.R.; Gatto, D.A. 2016. Physical and Mechanical Properties of Fast-Growing Wood Subjected to Freeze-Heat Treatments. BioResources 11(4): 10378-10390. https://ojs.cnr.ncsu.edu/index.php/BioRes/article/view/BioRes_11_4_10378_Missio_ Fast_Growing_Wood_Freeze_Heat

Navi, P.; Pizzi, A. 2015. Property changes in thermo-hydro-mechanical processing. Holzforschung 69(7): 863-873. https://doi.org/10.1515/hf-2014-0198

Pelit, H.; Budakçi, M.; Sönmez, A. 2018. Density and some mechanical properties of densified and heat post-treated Uludağ fir, linden and black poplar woods. Eur J Wood Wood Prod 76(1): 79-87. https://doi.org/10.1007/s00107-017-1182-y

Pelit, H.; Sönmez, A.; Budakçi, M. 2015. Effects of Thermomechanical Densification and Heat Treatment on Density and Brinell Hardness of Scots Pine (Pinus sylvestris L.) and Eastern Beech (Fagus orientalis L.). BioResources 10(2): 3097-3111. https://ojs.cnr.ncsu.edu/index.php/BioRes/article/view/BioRes_10_2_3097_ Pelit_Thermomechanical_Densification_Heat_Treatment

Pertuzzatti, A.; Missio, A.L.; Cademartori, P.H.G.; Santini, E.J.; Haselein, C.R.; Berger, C.; Gatto, D.A.; Tondi, G. 2018. Effect of Process Parameters in the Thermomechanical Densification of Pinus elliottii and Eucalyptus grandis Fast-growing Wood. BioResources 13(1): 1576-1590. https://ojs.cnr.ncsu.edu/index. php/BioRes/article/view/BioRes_13_1_1576_Pertuzzatti_Process_Parameters_Thermomechanical_Pinus_ Eucalyptus

Pertuzzatti, A.; Missio, A.L.; Conte, B.; Souza, S.C.; Santini, E.J.; Haselein, C.R. 2016. Physical properties of Pinus elliottii var. elliottii thermally treated wood under two different atmospheres. Brazilian Journal of Wood Science 7(1): 7-15. http://dx.doi.org/10.12953/2177-6830/rcm.v7n1p7-15

Sears, C. 1900. Process of preparing wood matrices. US Patent No 646,547. Cleveland, Ohio, USA. 
Sözbir, G.D.; Bektaş, İ.; Ak, A.K. 2019. Influence of combined heat treatment and densification on mechanical properties of poplar wood. Maderas-Cienc Tecnol 21(4): 481-492. http://dx.doi.org/10.4067/S0718$221 \times 2019005000405$

Ulker, O.; Imirzi, O.; Burdurlu, E. 2012. The effect of densification temperature on some physical and mechanical properties of scots pine (Pinus sylvestris L.). BioResources 7(4): 5581-5592. https://ojs.cnr. ncsu.edu/index.php/BioRes/article/view/BioRes_07_4_5581_Ulker_Densification_Temperature_Properties_ Scots_Pine

Unsal, O.; Candan, Z.; Korkut, S. 2011. Wettability and roughness characteristics of modified wood boards using a hot-press. Ind Crops Prod 34(3): 1455-1457. https://doi.org/10.1016/j.indcrop.2011.04.024

Wålinder, M.E.P.; Gardnerb, D.J. 1999. Factors influencing contact angle measurements on wood particles by column wicking. J Adhes Sci Technol 13 (12): 1363-1374. https://doi.org/10.1163/156856199X00523

Welzbacher, C.R.; Wehsener, J.; Rapp, A.O.; Haller, P. 2008. Thermo-mechanical densification combined with thermal modification of Norway spruce (Picea abies Karst) in industrial scale - Dimensional stability and durability aspects. Holz Roh Werkst 66: 39-49. https://doi.org/10.1007/s00107-007-0198-0

Wentzel, M.; Brischke, C.; Militz, H. 2019. Dynamic and static mechanical properties of Eucalyptus nitens thermally modified in an open and closed reactor system. Maderas-Cienc Tecnol 21(2): 141-152. http://dx.doi.org/10.4067/S0718-221X2019005000201

Wolcott, M.P.; Kamke, F.A.; Dillard, D.A. 1990. Fundamentals of flakeboard manufacture: viscoelastic behavior of the wood component. Wood Fiber Sci 22(4): 345-361. https://wfs.swst.org/index.php/wfs/ article/view/2018 